\title{
MEASURING THE QUALITY OF SIGNS FOR OBJECTS IN THE ECONOMY
}

\author{
Lyudmyla Malyarets'; Oleksandr Dorokhov ${ }^{2}$ \\ ${ }^{1}$ Department of Mathematics, Faculty of Finance, \\ Kharkiv National University of Economics, Kharkiv, Ukraine \\ ${ }^{2}$ Department of Information Systems, Faculty of Economics Informatics, \\ Kharkiv National University of Economics, Kharkiv, Ukraine \\ 2aleks.dorokhov@meta.ua
}

\begin{abstract}
The problems of measuring the quality attributes for different objects in the economy were considered. This article used methods of value measuring in the economy that were determined by the existing types. In this, it must distinguish between direct primary measurement, indirect measurement, joint and combined measurement. The different ways to solve it on the basis of joint measurement of qualitative and quantitative attributes inherent to economic facilities that were explored. Stages and elements of the quantities measurement processes in the economy were classified and analyzed. The corresponding mathematical methods and tools depending on the objectives and procedures of measurements were determined. The conceptual representation of an integral quality of the object in the economy as a generalizing indicator was proposed. It finds that it is possible to make general conclusions that underestimate the role of non-metric signs in the characterization of the object that is explained by their insufficient study and poorly developed mathematical tools to measure them.
\end{abstract}

Keywords: quantities measurement in economy, object quality assessment, qualitative methods in economics

\section{INTRODUCTION}

Measuring the quality of attributes for objects in the economy is a very complex problem. It touches the foundations of quantities measurement in economics, in conditions of the lack of universally accepted and common general concepts of measurement and evaluation for quality attributes of economic objects of different nature and essence. However, consideration and resolution of this problem are extremely necessary to ensure the integrity of the data and the results of their subsequent analysis of the economy.

If it is possible to distinguish one property from another for the economic object qualitatively, then it is possible to quantify it, to identify the units and methods of measurements, and the value of the properties under consideration. Thus, forming conditions for the formalization of the properties of the object to the signs and further studying this object using these signs, for example, is the measurement process in the economy (Malyarets, 2006; Ponomarenko \& Malyarets, 2009).

\section{METHODS}

Methods of value measuring in the economy are determined by their existing types. In this, we must distinguish between direct primary measurement, indirect measurement, joint and combined measurement. Highlighted types of measurement can be regarded as procedures of variables 
measurement technology. It is expedient to allocate the following elements of the measurement process in the economy: (1) object, measuring the quality of attributes for objects in the economy is a very complex problem as it touches the foundations of quantities measurement in economics. It is due to the lack of universally accepted and common general concepts of measurement and evaluation for quality attributes of economic objects of different nature and essence. However, consideration and resolution of this problem are extremely necessary to ensure the integrity of the data and the results of their subsequent analysis of the economy. If it is possible to qualitatively distinguish one property from another for the economic object, then it is possible to quantify it. It is also possible to identify the units and methods of measurements and the value of the properties under consideration. Thus, forming conditions for the formalization of the properties of the object to the signs and further studying this object using these signs, i.e., the measurement process in the economy (Malyarets, 2006; Ponomarenko \& Malyarets, 2009). (2) Sign, the magnitude of the sign, the value of magnitude, means for measuring, methods, conditions, technologies, results, measurement errors, and the system of measurers. The means of value measuring in economics are the scales and various indicators (Borie, 2016; Knorring, 1983; Turk, 2011). Measurement methods depend on the kind of values; technical, economic, statistical and mathematical methods. The conditions of measurements can be manufacturing, accounting, statistical, and researching (Malyarets, 2006).

In metrology, the definitions of the contents of separate individual elements of measurement are considered the science of measurement, although they refer only to the physical quantities. However, in this article, it is considered as features of the content of the measurement process which are due to the peculiarities of measurements in economics. Thus, the general scheme of stages for measuring of signs values in economics is shown in Figure 1.

Taking into account the meaningful sense of values in economics, it is advisable to consider the measurement technology in the form of five procedural blocks; they are the procedure of formulation, the procedure of preparation, initial measurement, secondary measurement, and the procedure of measurement errors control. Each mentioned procedure is different by content and complexity, but only the third procedure that involves direct measurement, i.e., the operationalization of the measurement is carried out exactly in it. The remaining procedures form the conditions of operationalization and obtainment of measurement results, and its numerical values with the necessary accuracy.

From the correct implementation of these procedures that depend on the accuracy of determining the values in the data analysis, consequently, the quality of economic management decisions shall be taken by the concerned person. The proposed scheme of the measurements stage of signs in the economy organizes this process well enough and is the only possible one in our opinion. Depending on the purpose of the value measurement, the individual stages of the overall technology may be missing. However, the logic in the sequence of actions, even in the abbreviated scheme should remain the same.

The choice of mathematical tools for the measurement of values is restricted. The practice of solving real problems in the economy shows the advisability to use mathematical methods, the list of which is given in Table 1 (Knorring, 1983). 


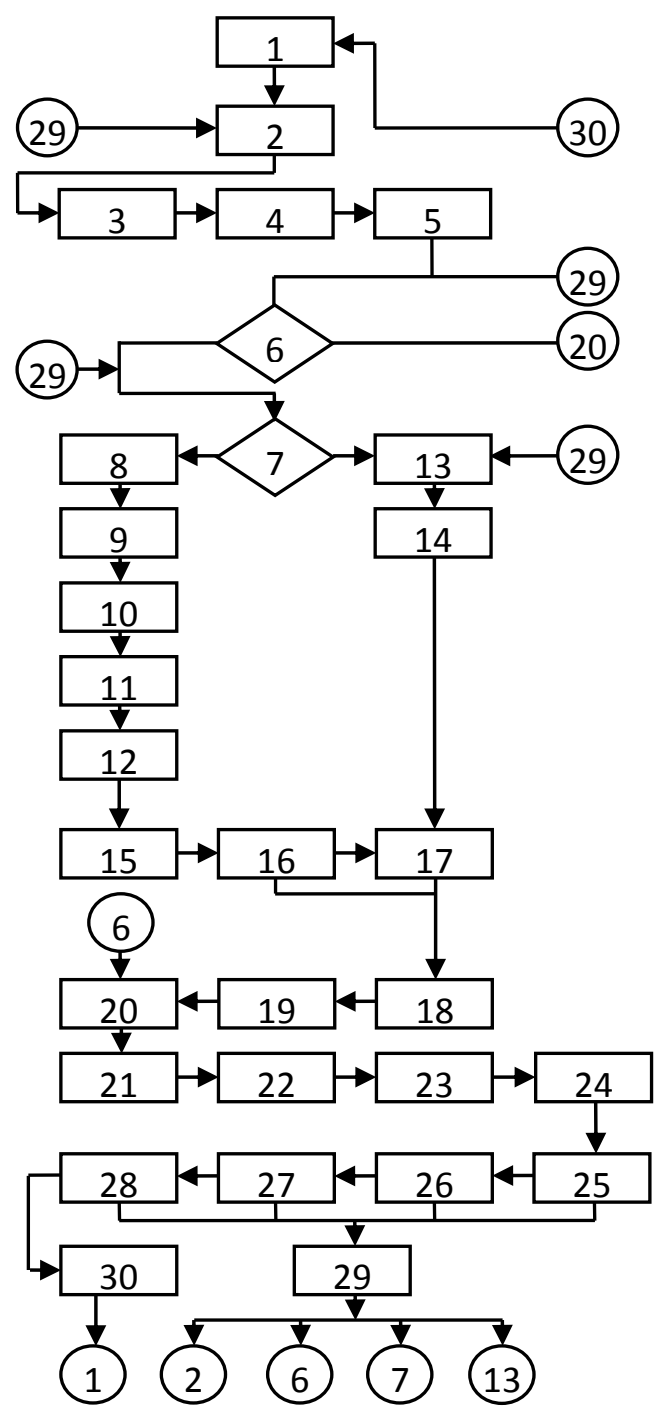

1. Analysis of the purpose of determining attribute magnitude of object

2. Cognitive model formation

3. Semantic model development

4. Creation of conceptual model

5. A priori definition of the object attributes as part of the socioeconomic system

6. Determination of attribute type (elementary or complex)

7. Determining of value type (metric or nonmetric)

8. Refinement of kind in the case of metric values

9. The choice of measurement method and its possible means

10. Preliminary choice of data processing algorithm

11. The priori estimation of measurement errors

12. Choice of measurement system

13. Determining the type of non-metric quantities and measuring scale

14. Checking of scale

15. Implementation of the technical measurement operation

16. Conversion of metric quantity to indicator

17. Giving quantities form for non-metric sign

18. Homogeneity determination for sign quantity

19. The choice of getting indicator method

20. Formation of conceptual model of complex sign

21. Development of mathematical model of complex sign

22 . The combined measurement of metric and non-metric values of complex sign

23. Conversion of complex sign value to general indicator

24. Formation of system of indicators

25. Analysis of the results on methodological errors

26. Analysis of the results on methodical errors

27. Analysis of the results on technical errors

28 . Analysis of the results on personality errors

29. Trouble shooting errors

30. Result report of value determining (considering errors), passage to a new measurement cycle

Figure 1 General Scheme of Stages for Measuring of Signs Values in Economics

Table 1 Tools to Determine the Values of Attributes and its Tasks

\begin{tabular}{lll}
\hline Measuring Phase & \multicolumn{1}{c}{ Recommended Tools } & \multicolumn{1}{c}{ Tasks of Toolkit } \\
\hline 1. Formulation & $\begin{array}{l}\text { Methods of structural logical analysis } \\
\text { and synthesis of measurements target }\end{array}$ & $\begin{array}{l}\text { Determining the purpose of measurements, the } \\
\text { development of cognitive, } \\
\text { conceptual models }\end{array}$ \\
2. Preparation & $\begin{array}{l}\text { Methods of structural logical analysis } \\
\text { and synthesis, methods of mathematical } \\
\text { statistics }\end{array}$ & $\begin{array}{l}\text { Definition of a sign kind, preparation of metric } \\
\text { and non-metric signs to measure its value }\end{array}$ \\
3. Initial & $\begin{array}{l}\text { Devices of measuring equipment, scales } \\
\text { of measurement, methods of managerial }\end{array}$ & $\begin{array}{l}\text { Converting physical and non-physical quantities } \\
\text { of elementary signs to indicator, giving the value } \\
\text { to non-metric sign }\end{array}$ \\
4. Secondary & $\begin{array}{l}\text { Methods of economic, mathematical and } \\
\text { statistical analysis, other mathematical } \\
\text { methods and models }\end{array}$ & $\begin{array}{l}\text { Conversion value to indicator; measuring the } \\
\text { of measurers for acceptance of managerial } \\
\text { decisions and further mathematical modeling }\end{array}$ \\
5. Errors Control & $\begin{array}{l}\text { Methods of mathematical statistics, } \\
\text { economic analysis, management }\end{array}$ & $\begin{array}{l}\text { Determination of the measurement errors at } \\
\text { different stages }\end{array}$ \\
\hline
\end{tabular}


In general, values in the economy can be divided into the basic physical values of elementary signs (which on this level of cognition can be quantified, extensive values) and derivatives physical values (obtained by means of basic physical values) (Danilov \& Lambert-Mogiliansky, 2005; Malyarets, 2006; Turk, 2011). In the second group, it can be distinguished such types of values, they are; (1) values with the dimension in physical units (obtained mainly by comparing the results and costs), (2) values without dimensions (coefficients, intensive values), (3) nonphysical values (metric values, obtained by certain transformations of physical values to the cost form of representation and their comparison), (4) synthesized metric values (define complex signs and objects in general), (5) Statistical metric values (showing mass signs for sets of objects in general, the extensive and intensive), (6) Non-metric values (reflecting qualitative characteristics of objects in economics, intensive, and qualitative, which are measured in non-metric scales). In general, this classification of values is represented in Figure 2.

The system of basic values (absolute and relative) signs of object

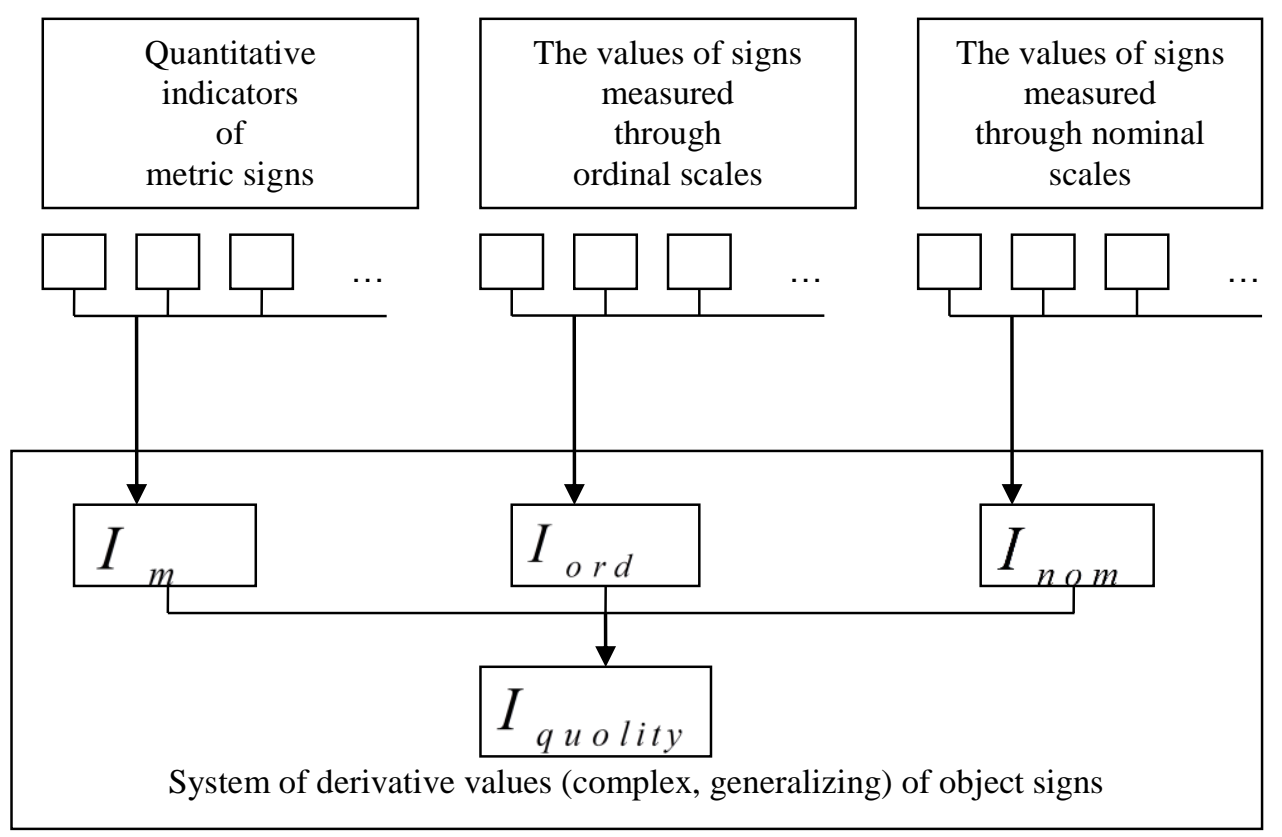

Figure 2 Classification for Values of Signs in the Economy

The classification in Figure 2 makes it possible to objectively measure different values in economics to display changes in the values of basic characteristics and properties. Such an approach allows integrated and holistic diagnosis, evaluation, and control as a change in the very structure of the properties of an individual object, as well as a hierarchical system of groups of objects (in a cut of regions, of branches of economy, of state). Moreover, it provides the fundamental basis ensuring the unity and the adequacy of the measurement of values in the economy.

\section{RESULTS AND DISCUSSIONS}

The overall quality of the object in the economy represented by generalized characteristic is defined by metric and non-metric signs. The characteristic may be measured under the condition of modeling the object, its characteristics, properties, functioning, and development processes. The most known methods for construction of generalizing indices are based on quantitative indicators, for example, on the metric values. However, the characteristics of the object, based only on quantitative properties, limits its estimations, and in some cases, lead to inaccuracies in these estimations. A well- 
known issue of compounds and interconnections of different values characterizing the same objects remains real in the traditional theory of general measurement and now (Gomme \& Rupert, 2007; Schwartz, 1985; Zeumo et al., 2012).

There are practically no recommendations for the construction of generalizing indicator of quality on the basis of non-metric values of the object and a fortiori, the joint measurements. The object in economics is characterized by a complex system of signs, separating it to quantitative and qualitative, extensive and intensive, metric and non-metric. Therefore, the synergistic manifestation of systemic properties of the object is accumulated in its overall quality, as this is conceptually and simplistically shown in Figure 3.

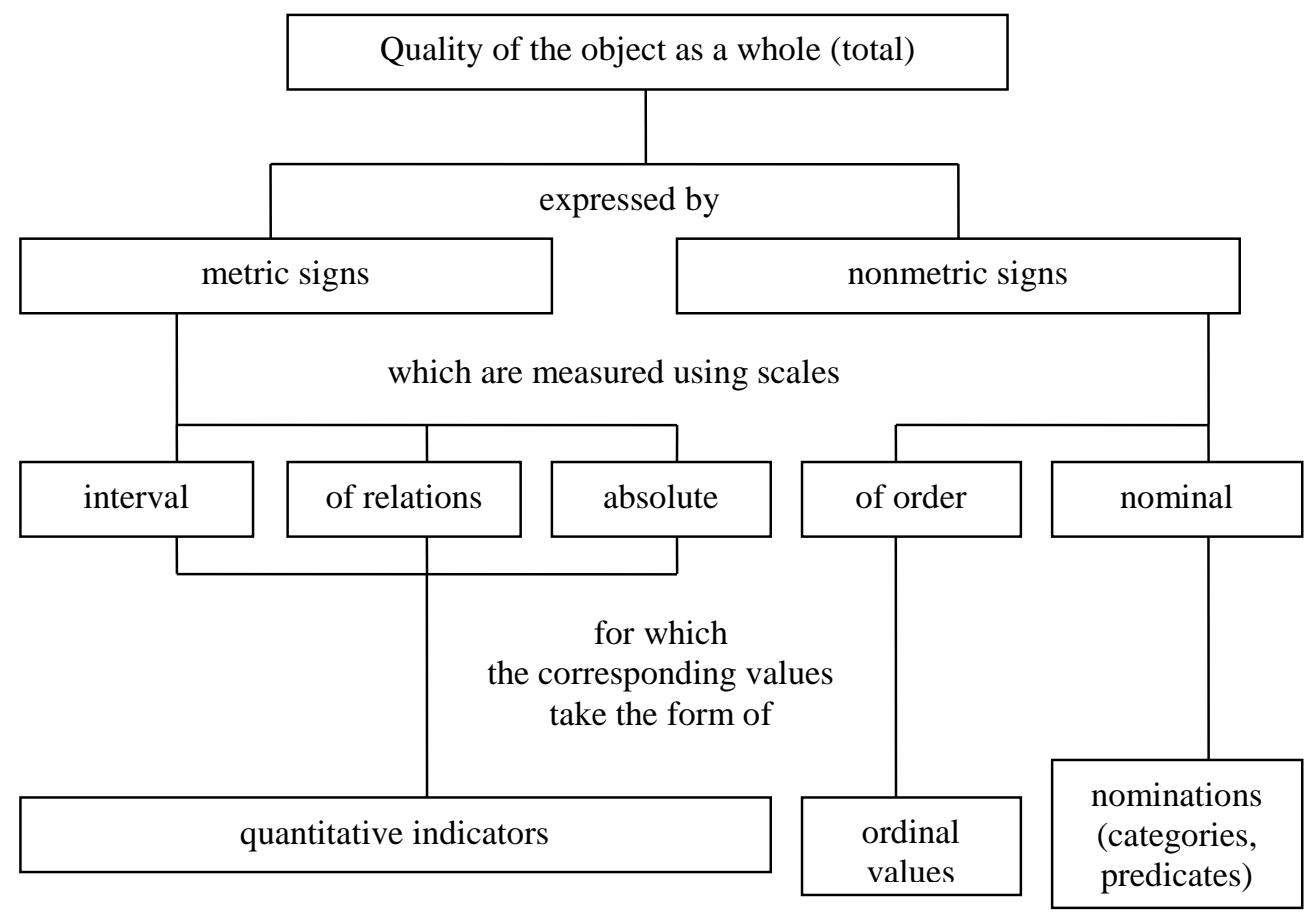

Figure 3 The Conceptual Representation of the Quality of the Object in the Economy

Measuring the quality of an object is a measure of co-manifestations of all its properties (characteristics), which in the form of the mathematical model of the overall quality has to be multiplicative. It should be remembered that the laws and regularities of nature are quantitatively expressed by the relationship of physical quantities in the form of their multiplication. Accordingly, the construction of an economic and mathematical model of the object (or its signs) to determine the quality, in the main, reduces to finding an adequate numerical representation of the multiplicative type. The joint expression of quantitative and qualitative properties of an object is measured by generalizing metric value, based on the multiplicative compound of partial metric and non-metric values, reduced to comparable form by calibration. Calibration or converting of different values to the same measure is carried out through conversion functions to which number belongs desirability function of the individual values (metric and non-metric). Note that in this case can be allowed a different kind of desirability functions. Forms and properties of the desirability function for quantitative elementary and complex features are discussed in papers (Saaty, 2008; Schwartz, 1985).

As it is known that each individual property of the object can be displayed on a separate sign, the value of which characterizes the measure (intensity) of this property, and form of the value of which is a partial indicator. Furthermore, the total value for the quality of an object is determined by the 
convolution of values of signs. This convolution can be done by various methods. The main problems in the modeling of generalizing indicators for quality of socioeconomic systems and the sequence of their solutions are presented in Figure 4 (Ponomarenko \& Malyarets, 2009).

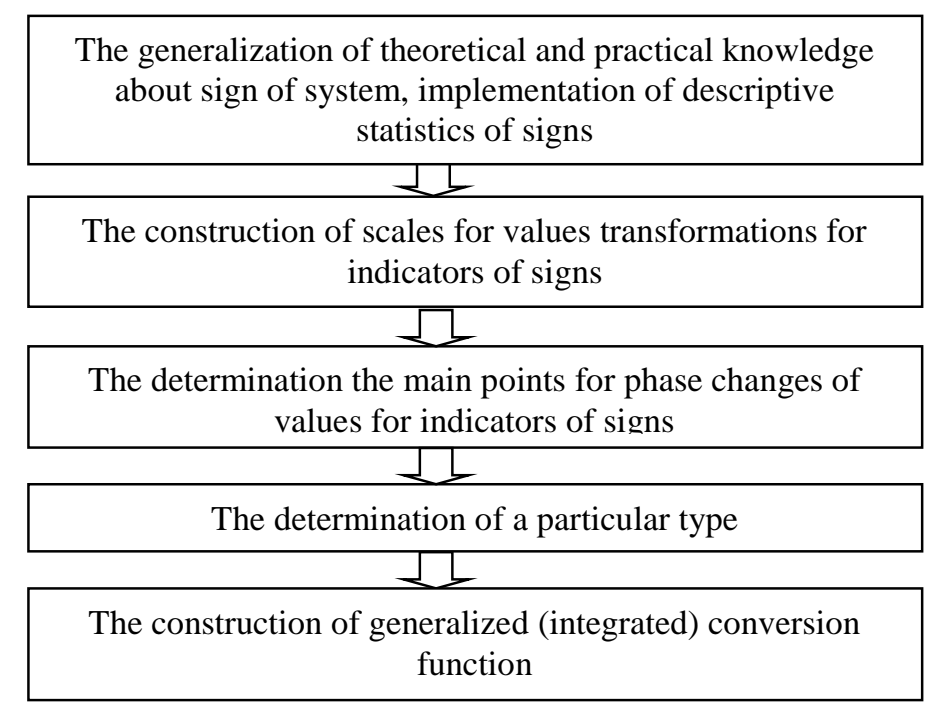

Figure 4 The Logic of Modeling for Generalizing Indicator of Object Quality in Economy

There are consideration ways to solve each problem separately. The first problem is the generalization of theoretical and practical knowledge about given sign, carrying out a statistical description of changing values for an indicator of the sign, and demonstrating its evolution. It can be solved based on the knowledge of experts (persons, making the decision) as a synthesis of theoretical and practical advances in the knowledge of this sign. It can also be solved by comparisons to the results of descriptive statistics to establish the contradictions in the actual change of sign quantity and taking into account the laws of its development. The second problem is the construction of conversion scales. By using it, it can carry out the conversion of economic indicators values (having their measurement units) in dimensionless scale. The solution here is conditioned by the results of solving the first problem and is a stage in the continuation of the measurement values of the economy because (due to transformation) the new values become comparable. There is evident that no matter how adequately built conversion scale is, it depends on the correctness of the results of procedures for secondary measuring the economy.

The multiplicative form of synthesizing (total, generalizing) function can be used for the utilization of private indicators construction models and arithmetization models for the synthesis of the composite indicator (Gomme \& Rupert, 2007). The grounds of this are the partial indicators represent the distribution functions of one-dimensional random values. Thus, their multiplication is a distribution function of - dimensional random variable with independent components. In this case, the value of summary indicator $Q(q)$ at the point $q^{0}=\left(q_{1}^{0}, \ldots, q_{m}^{0}\right)$ can be interpreted as the proportion of objects that having all the separate indicators values less than the value of $q_{1}^{0}, \ldots, q_{m}^{0}$ because the predominates probability that randomly chosen object will be for all particular criteria concede to the corresponding $q=\left(q_{1}, \ldots, q_{m}\right)$.

The geometric average $Q_{*}(q)$ is one of the most used generalizing average values that well studied from the standpoint of auto-arithmetization of numerical scales. The generalization of the 
concept of auto-arithmetization for real numbers scale, obtained through the use of isomorphisms between the set of all real numbers and its various subsets, allows expanding the class of continuous strictly monotone mappings $\varphi$, which are used to make various types of generalized average $Q_{+}^{\varphi}(q)$ (Hovanov, 1996).

Note that the partial functions calibrating values (normalizing functions) must be monotonous and can be interpreted as functions of the distribution of some random values. The domain of definition for the non-monotonic function can be separated into a small number of connected areas of monotonicity. It can also introduce the appropriate amount of positive particular indicators, monotonically dependent on corresponding initial characteristics. Danilov \& Lambert-Mogiliansky (2005) have proved the feasibility of using conversion functions $y_{i j}$ for the values of quantitative indicators (desirability functions) that having certain tendencies of change. For bilateral asymmetric development, here are the tendencies of signs:

$$
y_{i j}=\left\{\begin{array}{l}
100 \cdot e^{-3\left(\frac{x_{i j}-a_{i}}{b_{i}-a_{i}}\right)^{2}}, \text { for } x_{i j} \leq a_{i}, b_{i}<a_{i}, \\
100 \cdot e^{-3\left(\frac{x_{i j}-a_{i}}{c_{i}-a_{i}}\right)^{2}}, \text { for } x_{i j} \geq a_{i}, c_{i}>a_{i},
\end{array}\right.
$$

where $a_{i}, b_{i}, c_{i}$ - fiducials values: $a_{i}$-the most appropriate value of the index $x_{i j}$ in which the transformation function reaches its maximum value 1 or $100 \% ; b_{i}, c_{i}\left(b_{i}<c_{i}\right)$-the unsatisfactory value of the index $x_{i j}$ (on both sides of the best value mentioned above) at which the transformation function reaches a value not greater than 0,05 or $5 \%$. When symmetrical trends are in the development of sign, the transformation function reaches the value 1 or $100 \%$ at $a_{i}=\frac{b_{i}+c_{i}}{2}$. At that function, it acquires much simpler form:

$$
y_{i j}=100 \cdot e^{-3\left(\frac{x_{i j}-a_{i}}{b_{i}-a_{i}}\right)^{2}} \text { or } y_{i j}=100 \cdot e^{-3\left(\frac{x_{i j}-a_{i}}{c_{i}-a_{i}}\right)^{2}} .
$$

For unilateral types of evolution, are used monotone functions:

$$
y_{i j}=\frac{100}{1+e^{-\frac{x_{i j}-p_{i}}{q_{i}-p_{i}}}}
$$

where $q_{i}$-values of the index $x_{i j}$ at which the transformation function reaches the value not less than 0,95 or $95 \% ; p_{i}$ - values of the index $x_{i j}$ at which the transformation function reaches the value 0,5 or $50 \%$.

Separate conversions of non-metric values are made using desirability functions of quality indicators that are measured by using a nominal and ordinal scale. In its turn, data desirability functions are discrete functions and are defined in the tabular form. A particular type of these functions is due to the specific traits of concrete non-metric values. 
Qualitative sign measured using a nominal scale is expressed by magnitude of intensity of the quality's display and may take the following nominations (conformity to five standard estimations on a scale of desirability for the values of quantitative signs (Danilov \& Lambert-Mogiliansky, 2005; Knorring, 1983; Schwartz, 1985) - very low, low, medium, strong, very strong. In expanded variant: very low, low, medium, enough strong, strong, very strong. The given list of nominations can be extended.

The qualitative sign can be represented by a variety of equivalent nominations that are not characterized by the intensity of manifestation of the value. A separate nomination of the quality sign is put into correspondence with the quantitative value of the desirability function. Finally, briefly mention the problem of constructing generalizing indicator of quality on the basis of ordinal (measured by ordinal scales) signs of production and business activities of the economic object. As mentioned above, the nonquantitative property of an object can be expressed quantitatively by means of its degrees of intensity (Danilov \& Lambert-Mogiliansky, 2005). Depending on the order or rank of degrees, it sets their quantitative estimations (points) and thus carries quality measurement using ordinal scales.

The established point, for example, 1, 2, 3, 4, 5, is the quantitative expression of quality nominations of object properties (very low, low, medium, strong, and very strong). In order to establish points in expressing the qualitative sign, various methodologies are developed and used. However, almost all of them are based on the stimulus of the measured value $S$ (Knorring, 1983). For a joint measure of ordinal signs, it is necessary to calibrate the set scores using desirability functions. In the article (Borie, 2016; Saaty, 2008) is given an example of calibration of ordinal signs according to a questionnaire survey and its processing. The essence of the approach that obtained scores is put into the correspondence of a certain value of the desirability function (in accordance with their importance and differences).

As an example of the implementation of the proposals for the development of a generalization indicator, the authors will determine the assessment of the foreign economic activity of the company "Turboatom" in the city of Kharkiv (Ukraine). The foreign economic activity of this enterprise is characterized by certain key economic indicators, which are different metric values. These are the performance indicators: $x_{1}$ - currency efficiency of export, $x_{2}$ - economic efficiency of export, $x_{3}$ efficiency of product sales in the domestic market. These are the indicators of changes dynamics $y_{1}$ index of the value of exported products, $y_{2}$-index of prices of exported products, $y_{3}$-physical volume index of exported products, $y_{4}$-index of structure of exported products, $y_{5}$-realization of the plan for export, $y_{6}$ - realization of the sales plan on the domestic market. These are the indicators of structural shifts and rational that use of funds $z_{3}$ - proportion of overhead costs in the cost of exports, and $z_{4}$ coefficient of return on funds invested in export operations.

According to the logic of developing a generalizing indicator, the value of each of the partial indicators of the enterprise during the last five years has been converted quarterly by function:

$$
y_{i j}=\frac{100}{1+e^{-\frac{x_{i j}-p_{i}}{q_{i}-p_{i}}}} .
$$



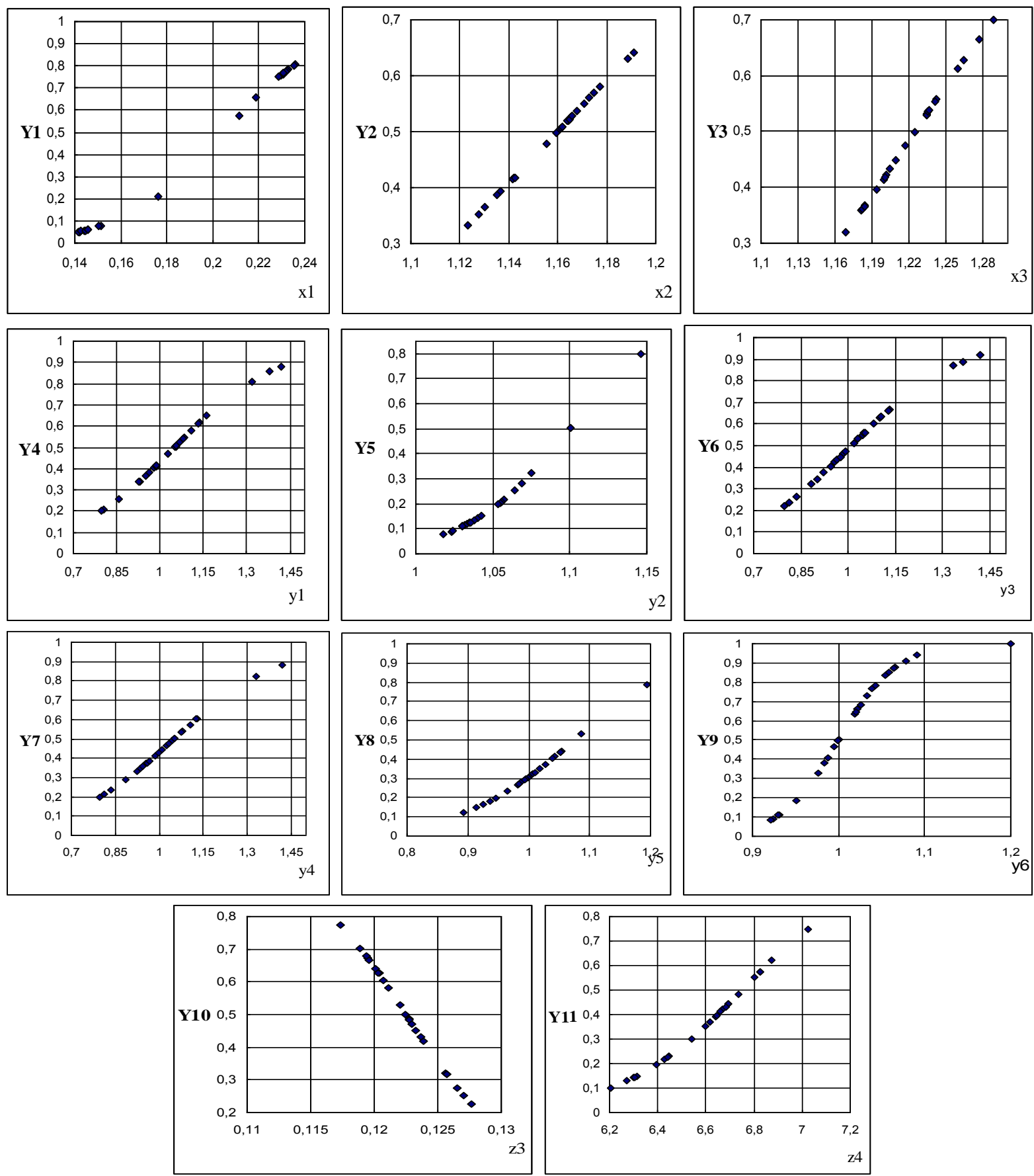

Figure 5 Functions of the Transformation of Partial Indices of the Enterprise

Figure 5 shows the graphs of transformation functions. The value of the generalization indicator is calculated as the geometric mean of integral indicator of efficiency of activity $\left(I_{x}\right)$, integral indicator of changes dynamics $\left(I_{y}\right)$, and integral indicator of structural shifts and rational use of funds $\left(I_{z}\right)$, namely $I_{1}=\sqrt[3]{I_{x} \cdot I_{y} \cdot I_{z}}$. 
Based on the graph in Figure 6, it can draw conclusions about the dynamics of the functioning of the foreign economic activity of this enterprise.

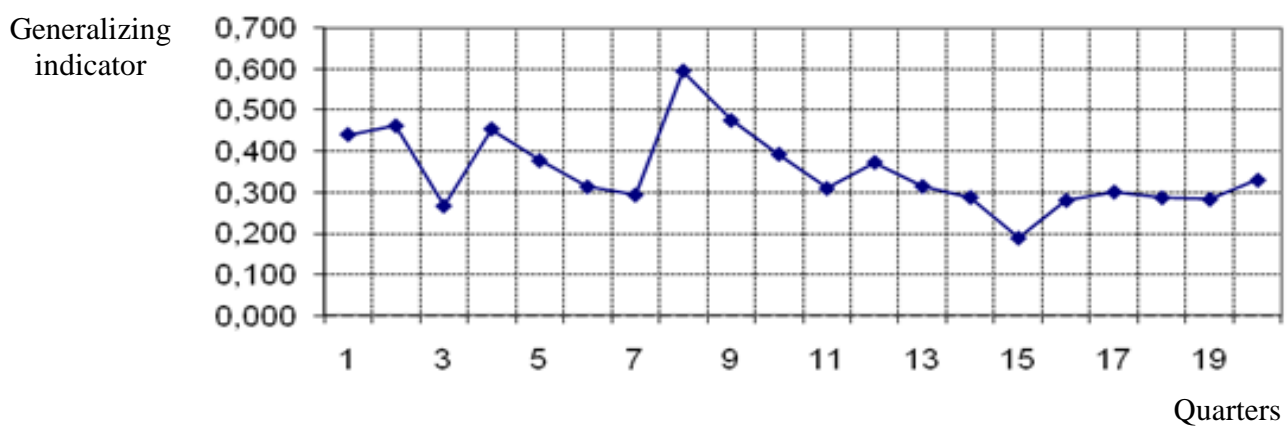

Figure 6 Dynamics of the Generalizing Indicator of Foreign Economic Activity for Enterprise "Turboatom" (2015-2016)

The dynamics of the generalization indicator demonstrate the tendency of non-rhythmic operation of the enterprise. It has a downturn and low values of the generalized index since the first quarter, except for the eighth quarter. After analyzing the indicators of foreign economic activity of this company, it can conclude that in general that the efficiency is low. And the economic efficiency of exports $\left(x_{2}\right)$ is less than the efficiency of sales of products in the domestic market $\left(x_{3}\right)$.In order to determine which factors caused the low values of the generalizing index of the enterprise in the future, it is expedient to construct a tree of the level of quality.

\section{CONCLUSIONS}

The proposed methodology for the construction of generalizing indicator of quality allows an architectonically measurement of all properties of an object in economics; metric and non-metric. Credibility and validity of the developed approach provide not only the collaborative synthesis and comprehensiveness measurement of metric and non-metric values but also the possibility of spatial and temporal comparisons of them and objects of measurement itself.

Existing attempts at constructing and assessing the quality of the objects in economics based on the combination of values obtained by different mathematical transformations. Considering them as the first approximation in the knowledge of the object, in principle, they should be not rejected. However, all methods are limited to the synthesis of metric or (at best) ordinal signs, without taking into account the nominal signs of the object. Thus, generalizing quality of the object should be determined by the formula $I_{y}=\sqrt[3]{I_{m} \cdot I_{\text {ord }} \cdot I_{\text {nom }}}$, where $I_{m}$ - generalizing quality of metric attributes index; $I_{\text {ord }}$ generalizing index of sign's quality on ordinal scales; $I_{n o m}$ - generalizing index of sign's quality on nominal scales. An alternative for more general case $I_{y}=\sqrt[N]{I_{m}^{n_{1}} \cdot I_{\text {ord }}^{n_{2}} \cdot I_{\text {nom }}^{n_{3}}}$, where $N=n_{1}+n_{2}+n_{3}$ , $n_{1}, n_{2}, n_{3}$-weight coefficients for the importance of signs. In summary, it is possible to make general conclusions that underestimate the role of non-metric signs in the characterization of the object that is explained by their insufficient study and poorly developed mathematical tools to measure them. 


\section{REFERENCES}

Borie, D. (2016). Error in measurement theory. GREDEG Working Papers 2016-09, Groupe de Recherche en Droit, Economie, Gestion (GREDEG CNRS)

Danilov, V., \& Lambert-Mogiliansky, A. (2005). Non-classical measurement theory: A framework for behavioral sciences. PSE Working Papers halshs-00590714, HAL.

Gomme, P., \& Rupert, P. (2007). Theory, measurement, and calibration of macroeconomic models. Journal of Monetary Economics, 54(2), 460-497.

Hovanov, N. (1996). Analysis and synthesis of indicators in an information deficit [Analiz isintezpokazateleypriinformatsionnom defitsite]. St. Petersburg: St. Petersburg University Publisher.

Knorring, V. (1983). Theoretical foundations of information and measuring equipment, basic concepts of the theory of scales [Teoreticheskiye osnovyinformatsionno-izmeritel'noytekhniki. Osnovnyye ponyatiyateorii shkal]. St.Petersburg: St.Petersburg University Publisher.

Malyarets, L. (2006). Measurement attributes of objects in economy: Methodology and practice [Vymiryuvannya oznakob'yektiv v ekonomitsi: metodolohiya ta praktyka]. Kharkiv: KhNUE Publisher.

Ponomarenko, V., \& Malyarets, L. (2009). Analysis of data in studies of socioeconomic systems [Analiz danykh u doslidzhennyakh sotsial'no ekonomichnykh system]. Kharkiv: KhNUE Publisher.

Saaty, T. (2008). Relative measurement and its generalization in decision making: Why pairwise comparisons are central in mathematics for the measurement of intangible factors theanalytichierarchy/networkprocess. RACSAM (Review of the Royal Spanish Academy of Sciences, Series A, Mathematics), 102(2), 251-318.

Schwartz, J. (1985). The neglected problem of measurement error in categorical data. Sociological Methods \& Research, 13(4), 435-466.

Turk, J. (2011). Science is measurement: muons, money and the Nobel Prize. International Journal of Pluralism and Economics Education, 2(3), 291-305.

Zeumo, V., Tsoukiàs, A., \& Some, B. (2012). A new methodology for multidimensional poverty measurement based on the capability approach. Working Papers hal-00874627, HAL. 